\title{
St John's Wort improves somatoform disorders
}

Muller T, Mannel M, Murck H, et al. Treatment of somatoform disorders with St John's Wort: a randomized, double-blind and placebo-controlled trial. Psychosom Med 2004;66:538-47.

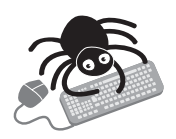

\section{Is St John's Wort extract (LI 160) effective and safe for somatoform disorders?}

\section{METHODS}

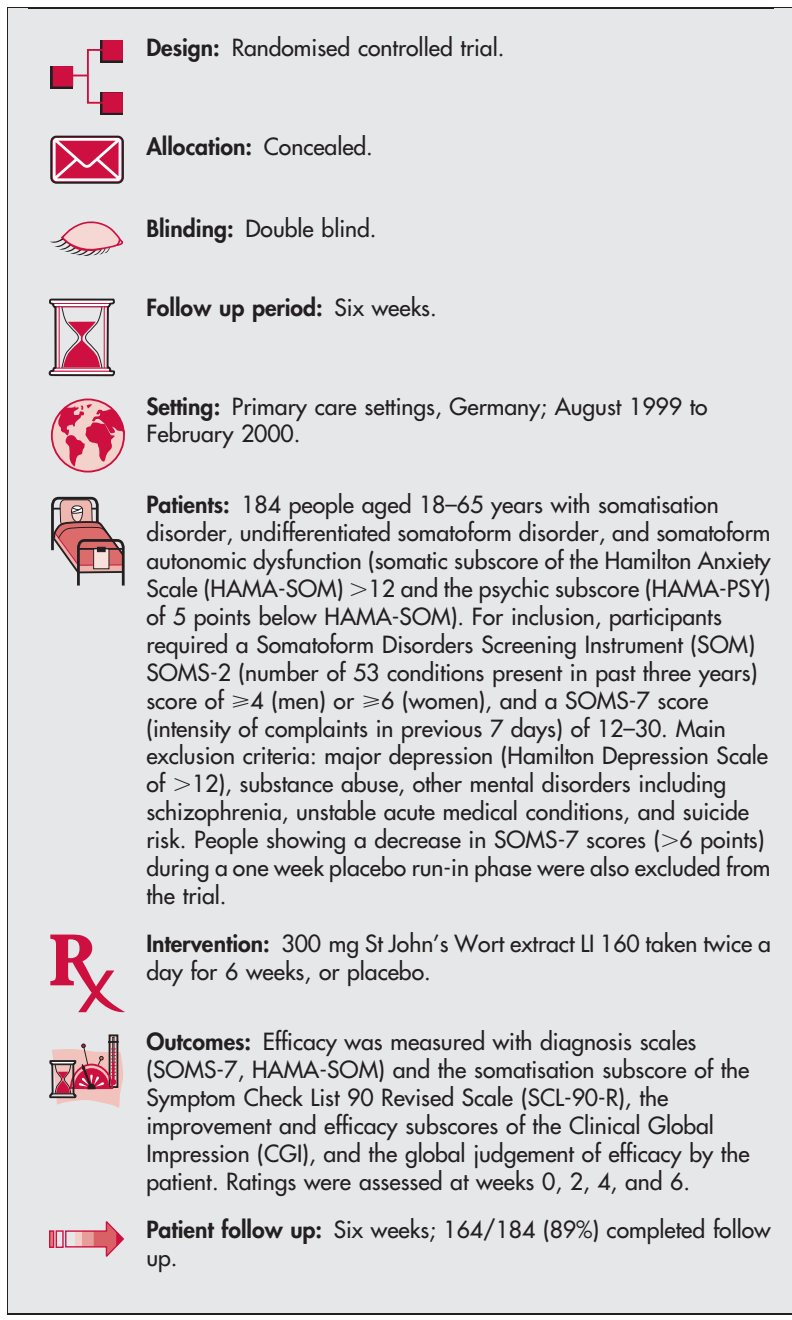

\section{MAIN RESULTS}

At 6 weeks, St John's Wort extract significantly reduced somatoform symptoms compared with placebo (see http://www.ebmentalhealth. com/supplemental for table). More people taking St John's Wort

For correspondence: Dr Thomas Müller, Department of Neurology, St Josef Hospital Bochum, Ruhr-University of Bochum, Gudrunstr 56, D-44791 Bochum, Germany; thomas.mueller@ruhr-uni-bochum.de

Sources of funding: Lichtwer Pharma GmbH, Berlin, Germany (manufacturers of St John's Wort supplements). were classed as responders compared with placebo $(45 \% \vee 21 \%$, $\mathrm{p}<0.0006$ )

\section{CONCLUSIONS}

$300 \mathrm{mg}$ of St John's Wort extract LI 160 significantly improves somatoform disorder symptoms.

\section{Commentary}

$\mathrm{n}$ traditional folk medicine and increasingly in more conventional practice, St John's Wort has been used for many different conditions including depression, anxiety, psychovegetative disturbances, myalgia, bronchitis, asthma, gall bladder disease and other gastrointestinal complaints, nocturnal enuresis, gout, and rheumatism. ${ }^{1}$ This purported spectrum of efficacy makes St John's Wort an ideal candidate for treatment of somatoform disorders. However evidence is scarce. Recent trends in trials for depression suggest that its effectiveness may be lower than previously assumed. ${ }^{2}$

The study by Müller et al is important, as it expands the available evidence for St John's Wort and somatoform disorder. Unfortunately, similar to the early depression trials, there are some methodological problems which may limit the clinical validity of the findings. For instance, placebo responders were to be excluded after the placebo run-in phase, leading to a bias in favour of St John's Wort even if patients were subsequently randomised. Nine patients dropped out at this stage, although it is not clear whether they were placebo responders. However three of the four reasons given, including withdrawal of consent, poor compliance, and adverse events, may create a similar bias. Also the trial was conducted over a six week period, a short time span considering the chronicity of somatoform disorders. Finally the study reports extremely low rates of adverse events. The authors concede that they did not specifically investigate this, but they do not consider the possibility that patients experiencing side effects might not attribute those to St John's Wort if they assumed that it was "natural" and hence safe. The significant potential of drug interactions by virtue of CYP $3 \mathrm{~A} 4$ and p-glycoprotein induction is not discussed. ${ }^{3}{ }^{4}$ However, this may be of importance in people with somatoform disorders also taking a variety of medications for their physical complaints.

Dr Ursula Werneke, MD, MSc, MRCPsych

Consultant Psychiatrist, Homerton University Hospital and Honorary

Senior Lecturer, Institute of Psychiatry, King's College, London, UK

1 In: Physicians' desk reference (PDR) for herbal medicines, 2nd edn. Montevale, New Jersey: Medical Economics Company, 2001.

2 Werneke U, Horn O, Taylor D. How effective is St John's Wort? The evidence revisited. J Clin Psych 2004;65:611-17.

3 Mannel M. Drug interactions with St John's Wort: mechanisms and clinical implications. Drug Saf 2004;27:773-97.

4 Peebles KA, Baker RK, Kurz EU, et al. Catalytic inhibition of human DNA topoisomerase Il $\alpha$ by hypericin, a naphthodianthrone from St. John's wort (Hypericum perforatum). Biochem Pharmacol 2001;62:1059-70. 